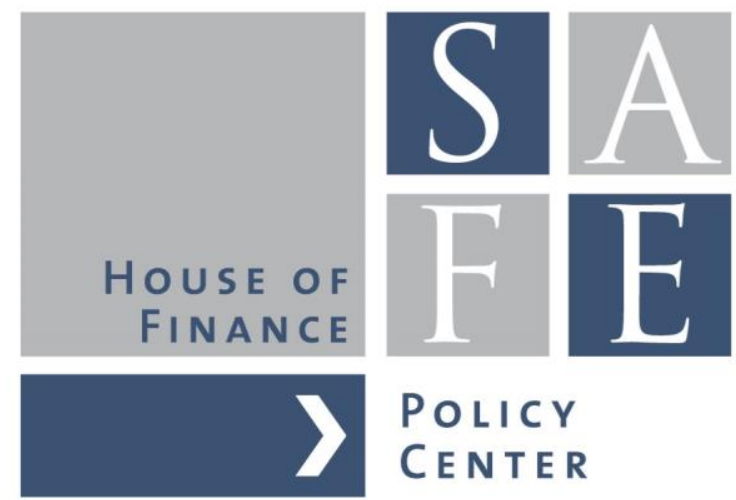

Jan Pieter Krahnen - Christian Wilde

\title{
Skin-in-the-Game in ABS Transactions: A Critical Review of Policy Options
}

SAFE Policy White Paper No. 46

SAFE I Sustainable Architecture for Finance in Europe A cooperation of the Center for Financial Studies and Goethe University Frankfurt 


\title{
SKIN-IN-THE-GAME IN ABS TRANSACTIONS: A CRITICAL REVIEW OF POLICY OPTIONS *
}

\author{
Jan-Pieter Krahnen and Christian Wilde ${ }^{\dagger}$
}

February 6, 2017

\begin{abstract}
This paper applies the theory of structured finance to the regulation of asset backed securities. We find the current regulation in Europe (Article 405 of the CRR) and the US (Section D of Dodd-Frank Act) to be severely flawed with respect to its key intention: the imposition of a strict loss retention requirement. While nominal retention is always $5 \%$, the true level of loss retention varies across available retention options between zero loss retention and full loss retention at the extreme ends. Based on a standard model of structured finance transactions, we propose a new risk retention metric $R M$ measuring the level of an issuer's skin-in-the-game. The new metric could help to achieve a better implementation of CRR/CRD-IV and DFA, by making disclosure of the $R M$-number compulsory for all ABS transactions. There are also implications for the operation of rating agencies. On a general level, the $R M$ metric will be instrumental in achieving simplicity and transparency in securitizations (STS).
\end{abstract}

Keywords: Structured finance, ABS, STS (simple, transparent, and standardized securitizations), regulation, retention, Capital, Dodd-Frank Act

JEL Classification: G2

\footnotetext{
${ }^{*}$ We gratefully acknowledge support by Deutsche Forschungsgemeinschaft and LOEWE Center SAFE. We thank Jeffrey Gordon and seminar participants at the 2017 Columbia-ECGI-Oxford CMU conference in Oxford for providing helpful comments.

${ }^{\dagger}$ Correspondence: House of Finance, Goethe University Frankfurt, Theodor-W.-Adorno Platz 3 (H29), 60323 Frankfurt am Main, Germany, Phone: +49 69798 33699, E-mails: krahnen@finance.uni-frankfurt.de, wilde@finance.uni-frankfurt.de
} 


\section{Introduction}

This paper suggests a new metric that captures the extent to which an ABS transaction (CDO, CLO, MBO, CMBO, RMBS, CDO square) embodies skin in the game. The metric, if implemented and disclosed, establishes transparency in an otherwise opaque market. The new metric also provides information on the extent to which incentive problems (adverse selection and moral hazard) will influence the performance of securitizations.

From the 2007 subprime mortgage lending crisis we have learned a lesson: Without a deductible of sufficient magnitude, originators of loans may not be motivated to engage in proper screening of loan applicants, nor are they interested in proper monitoring over the life of the loan contract. As a remedy, loan originators should keep part of the default risk on their own books, i.e. hold on to sufficiently large skin in the game. This will help to align the incentives of the originator with those of the investor (Franke and Krahnen (b), see also Gorton and Metrick (2012) and Fons (2008)).

The paper is organized as follows. In Section 2 we revisit the theoretical and empirical literature on ABS and give an overview of the current regulation and the various retention specifications it offers. Section 3 presents modeling techniques for structured finance products and introduces examples of ABS transactions. Section 4 applies the presented modeling techniques to compare different retention rules for ABS, particularly the so-called vertical and horizontal withholding rules. An easy-to-understand metric, which we label the retention metric $R M$ is developed, based on the analysis in the previous section. We show that true risk retention varies significantly across the alternative rule specifications, ranging from the maximum level of one hundred percent of an issue's default risk to much lower retention levels, all the way down to zero percent. Section 5 discusses broader policy implications of an improved retention metric, in particular for regulators and rating agencies. The disclosure of a standardized and rigorous retention metric, like the $R M$, will strengthen the development potential of ABS markets, as it lowers the cost of capital for securitization transactions. 


\section{Risk retention (skin-in-the-game) as a key characteristic of as- set backed securities}

\section{$2.1 \quad$ Literature review}

The market for asset backed securities has increased sharply since the mid 1990s and with it rose the interest in the theory of structured finance, and the empirical evidence. The early (precrisis) literature focused on the statistical properties asset backed securities, resulting from the pooling and tranching of debt assets, like mortgages and corporate loans, or credit card loans. The newly created securities are characterized by different levels of seniority (Coval et al. (2009), Franke and Krahnen (a)).

Early empirical work on European CDOs has found the size of first loss (equity) pieces in transactions with several mezzanine tranches to be 'small' in absolute terms, but at the same time to be 'large' relative to expected loss. Hänsel and Krahnen (2008) find the exceedance of retained risk over expected loss to average $+50 \%$ of the latter, for a sample of 78 European CDOs issued between 2002 and 2006. For these issues, a potential risk transfer from banks as originators of the pooled loan assets to capital markets (e.g. institutional investors) through a securitization transaction, therefore, is predominantly shaped by the allocation of the juniormost tranche, the so-called equity piece (first-loss piece).

The theoretical literature on loan sales and structured finance transactions has concentrated from its beginnings on the hazard of incentive misalignment, see for example Innes (1990), Gorton and Pennacchi (1995), DeMarzo (2005), Hellwig (2009) and Hébert (2015). From these, and other, papers it became clear that a theory of structured finance is not only about the optimal design of asset backed securities, but is actually about the most fundamental choice between debt and equity, the core subject of corporate finance.

In this spirit, Hébert (2015), derives the conditions under which the issuance of debt mitigates the trade-off between debt and equity incentive problems, already addressed in the classic article by (Jensen and Meckling (1976)).

Hébert (2015), and also Hartman-Glaser et al. (2012) derive conditions for optimality of a contractual design. Hébert finds equity issuance, i.e. first loss retention, and also debt issuance, to be needed for optimality. A role for regulation is identified in Chemla and Henessy (2014) who find that originators do not fully internalize the signaling value of retention. 
There has been a lot of empirical work since the outbreak of the financial crisis in 2007; a detailed description of the ABS market is in Ashcraft and Schuermann (2007). Keys et al. (2010) find evidence for a negative impact of securitization (likelihood) on ex-ante screening effort by the issuer. Begley and Purnanandam (2013) and Ashcraft et al. (2014) both find additional support for the risk mitigation hypothesis of retention. Begley and Purnanandam (2013) rely on 163 securitization deals with more than 500,000 underlying residential mortgage loans in the period 2001-2005.

They find an inverse relationship between the size of the equity tranche and the level of foreclosure experienced among borrowers in the asset pool. Based on 483 CMBS deals issued in between 1995 and 2010, Ashcraft et al. (2014) find similarly the probability of senior tranche default to be inversely related to the size of the first loss piece. Kara (2015), in a differencein-difference exercise using euro-denominated syndicated loans, find evidence in favor of a more general quality deterioration hypothesis, where the quality of securitized loans deteriorates more than an otherwise identical sample of non-securitized loans. The authors interpret their finding as evidence for the incentive effect of loss retention.

While these empirical studies support the hypothesis of incentive effect of securitization design, particularly the size of the equity piece, none of the studies has used actual loss retention data. Instead, all studies refer to nominal size of (junior) tranches without considering neither the actual shape of the loss distribution, nor the actual allocation to originator or investor. A notable exception is Scholz (2014), using US bank holding data on securitization and retention of non-agency mortgage loans.

On the first issue, the shape of the loss rate distribution across different issues, see Hänsel and Krahnen (2008) and Franke et al. (2012). These authors find that the size of the junior-most tranche and its share in the loss allocation can differ widely across issues. Hence, a large equity piece is not necessarily implying that the share of the loss distribution covered by it is also large. In fact, Hänsel and Krahnen (2008) find some evidence of an inverse relationship between the nominal size of the equity piece and its expected loss coverage.

A stronger empirical test of the retention hypothesis, therefore, needs to capture effective retention rather than the nominal size of the first loss piece. Effective retention captures the size of the default loss retained by the issuer together with the likelihood of the loss event occurring. An easy way to measure effective retention relies on the expected loss of retained exposures, relative to total expected loss. The rest of the paper develops this idea into a workable concept 
of effective retention measurement, relying on the data typically accessible for analysts.

The a new metric - which is labeled the retention metric $R M-$ can then be applied to evaluate the effective retention implied by the existing regulatory options offered in the implementation rules of the regulation. What are these options?

\subsection{Skin-in-the-game in post-crisis regulation: the case of the EU (CRR, Art. 405) and the Dodd-Frank Act in the US}

Motivated by the experiences during the 2007/2008 financial crisis, and in accordance with the emerging academic literature on the sources of the systemic risk event in those years, regulators around the world have tried to counter the observed loss of asset qualities in securitization processes through appropriate regulation. Most prominently, the regulators in the US and in the EU have amended existing rules by making a minimum level of skin-in-thegame held by the originator or some other controlling party, like the deal servicer, a mandatory element of all publicly issued deals. The relevant regulations are the Dodd-Frank Wall Street Reform and Consumer Protection Act in the US (see DFA (2010) Title IX, Subtitle D in: https://www.gpo.gov/fdsys/pkg/BILLS-111hr4173enr/pdf/BILLS-111hr4173enr.pdf) and the Capital Requirement Directive in the EU, CRR/CRD IV (see Article 405 in EC (2013): http://eur-lex.europa.eu/LexUriServ/LexUriServ.do?uri=OJ:L:2013:321:0006:0342:EN:PDF).

These two regulations are quite similar, though not identical in the specifications of what the term "retention" actually means. In the Dodd-Frank Act (henceforth DFA), Title IX is on "investor protections and improvements on the regulation of securities", with subtitle D dealing with "improvements of the asset-backed securitization process" (DFA Sections 941-950). Section 941 specifies the regulation of credit risk retention. Implementation provisions have been defined by the SEC in 2014, see https://www.sec.gov/rules/final/2014/34-73407.pdf. The new rules allow for several different ways how to fulfill the $5 \%$ retention requirement. The "Final Rule" defines a menu of options, including a vertical risk retention, a horizontal risk retention, and any combination of the two, based on the fair value of the tranches.

Similarly, the European regulation stipulates as follows (CRR, Art. 405): Only any of the following qualifies as retention of a material net economic interest of not less than 5\%:

(a) retention of no less than 5\% of the nominal value of each of the tranches sold or transferred to the investors 
(b) in the case of securitisations of revolving exposures, retention of the originator's interest of no less than $5 \%$ of the nominal value of the securitised exposures;

(c) retention of randomly selected exposures, equivalent to no less than 5\% of the nominal value of the securitised exposures, where such exposures would otherwise have been securitised in the securitisation, provided that the number of potentially securitised exposures is no less than 100 at origination;

(d) retention of the first loss tranche and, if necessary, other tranches having the same or a more severe risk profile than those transferred or sold to investors and not maturing any earlier than those transferred or sold to investors, so that the retention equals in total no less than $5 \%$ of the nominal value of the securitised exposures;

(e) retention of a first loss exposure not less than 5\% of every securitised exposure in the securitisation.

Both regulations, DFA and CRR, offer a menu of implementation options for the fulfillment of the $5 \%$ retention requirement. All specifications, whether horizontal, vertical or any other form, are defined in terms of nominal value (in US: fair value) of the issued tranches.

The terms 'horizontal' and vertical' refer to the graph of the layered tranches, from the bottom (equity piece), via middle-level mezzanine pieces, and all the way up to the top senior and super-senior tranches, as in Figure 1. Vertical retention implies withholding a percentage of each tranche, ranging from the first loss piece to all mezzanine tranches, and the senior-most tranche. For example, by retaining $5 \%$ of each tranche, overall retention equals $5 \%$ of the issue volume, fulfilling the regulatory requirement.

Horizontal retention, in contrast, refers to withholding the junior-most tranche, and if needed the most junior mezzanine tranche, followed by the second most junior mezzanine tranche, etc., until the retained issue volume reaches the $5 \%$ threshold. With regard to Figure 1, vertical retention is represented by a slice of all issued notes on the right side of the graph, while horizontal retention is shown as the threshold amount. According to the regulation, both areas have to be of equal issue volume - but as can be seen by eyeballing, the extent to which losses in default states are retained differs widely between the two options, being much bigger in the case of a horizontal retention.

Under the US regulation, a L-shaped retention requirements is also admissible, implying a combination of vertical and horizontal withholding, i.e. retention of a first loss plus a certain 
percentage of all remaining tranches.

The major take-away from this section is twofold. First, retention is defined in money terms, not in terms of the risk contained in the respective tranches. Second, the regulatory implementation rules offer a menu of retention options that, since they are defined in in money terms, may differ with respect to the effective risk retained.

\section{Measuring default risk in ABS transactions}

In the next section, we will introduce a technique to derive an estimate of the distribution of default loss expectation across the different tranches (or layers) of an ABS transaction. The general methodology is widely used, e.g., by rating agencies in their evaluation on asset backed securities, and by investment banks in their advisory work on the structuring of asset portfolios for securitization purposes. The methodology will serve subsequently to develop a simple metric of loss retention.

\subsection{Model Setup for ABS}

Taking the model setup from Krahnen and Wilde (2014), we apply a firm-value model to capture the occurrence of obligor default. More precisely, we apply a structural one-factor correlated default model as in Schönbucher (2000) and Vasicek (1987). The driving factor is a market factor, and company value is modeled as the interplay of the market factor and a company-specific, idiosyncratic risk factor. The chosen one-factor approach corresponds with the methodology used in the Basel-II documents. We model company value $V_{n, t}$ of each obligor $n \in 1,2, \ldots, N$ at

any time $t$ before maturity as being driven by a generalized macroeconomic factor $Y_{t}^{M}$ that is common to all securities, and an idiosyncratic component $\epsilon_{n, t}$ :

$$
V_{n, t}=\sqrt{\rho_{n}^{M}} Y_{t}^{M}+\sqrt{\left(1-\rho_{n}^{M}\right)} \epsilon_{n, t}
$$

with $Y_{t}^{M} \sim \Phi(0,1)$ and $\epsilon_{n, t} \sim \Phi(0,1)$, where $\Phi(0,1)$ denotes the standard normal distribution. Thereby, we obtain correlated asset values of obligors. In case the sensitivities $\sqrt{\rho_{n}^{M}}$ of firm values to the macroeconomic risk factor are the same for all obligors $n$, then $\rho_{n}^{M}$ corresponds to the mutual correlation coefficient for all assets. 
Obligor $n$ is assumed to default if at any time $t$ the value $V_{n, t}$ of its assets lies below the exogenously given default boundary $D_{n}$, i.e. $V_{n, t}<D_{n} . V_{n, t}$ is assumed to be normally distributed and is standardized such that $V_{n, t} \sim \Phi(0,1)$.

There is a simple relation linking every default boundary $D_{n}$ to a particular default probability $p_{n}$ :

$$
D_{n}=\Phi^{-1}\left(p_{n}\right)
$$

Usually, a fraction of the notional amount can be recovered in case of default. Let $\psi_{n}$ denote the recovery rate and $\theta_{n}$ the exposure size of security $n$. Portfolio loss is given as the sum of individual loan losses. We define the portfolio loss rate $P L R$ as the final value at maturity of portfolio loss divided by the final value of all promised payments until maturity:

$$
P L R=\frac{\sum_{n=1}^{N} 1_{\left\{T_{n}>\tau_{n}\right\}} \cdot \theta_{n} \cdot\left(F_{n} \cdot\left(1-\psi_{n}\right) \cdot \exp ^{r\left(T_{n}-\tau_{n}\right)}+C_{n, \tau_{n}, T_{n}}\right.}{\sum_{n=1}^{N} \theta_{n} \cdot\left(F_{n}+C_{n, 0, T_{n}}\right)},
$$

where $1_{\left\{T_{n}>\tau_{n}\right\}}$ is an indicator function taking the value one if security $\mathrm{n}$ defaults during its lifetime and zero otherwise. $T_{n}$ represents maturity of security $n$, and $t_{n}$ is the time of default. $F_{n}$ denotes the redemption value and $C_{n, s_{n}, t_{n}}$ represents the present value at time $t_{n}$ of all coupon payments for security $n$ paid in the time interval $\left[s_{n}, t_{n}\right]$. All payoffs are discounted with interest rate $r$.

The applied firm value model (Eq. 1) is suitable for a simulation exercise.

\subsection{Model Implementation}

In the implementation, we do not need to apply simplifying assumptions to determine the loss distribution of the underlying portfolio. Instead, we are able to fully profit from the Monte Carlo Simulation procedure. Analytical approaches often rely on limiting assumptions, e.g. that the portfolio is composed of an infinite number of securities with identical characteristics. Thus, analytical models to some extent may be suitable for sensitivity analyses, but Monte Carlo Simulation is more appropriate for real-world applications. All individual securities in the portfolio can be accounted for by their specific exposure size, recovery rate, default probability, and maturity. Furthermore, Monte Carlo Simulation allows to differentiate between obligors and individual securities. The occurrence of joint obligor defaults is modeled by accounting for 
the sensitivity of each individual obligor to the common factor.

The loss distribution is simulated in 5 steps: First, a realization of the macro factor is simulated until maturity. Subsequently, default scenarios are generated for all individual obligors in the portfolio. Default occurs, if the simulated firm value of an obligor, based on realizations of the macro factor and an idiosyncratic term, falls below the default boundary which is determined by the default probability of the obligor. In the third step, individual loan losses are obtained by applying a recovery rate to loan default. Fourth, portfolio loss is given as the sum of realized individual loan losses. This corresponds to one realization in the simulation. Fifth, many simulation runs yield the loss distribution of the entire portfolio.

The loss distribution depends on various input factors that may be grouped into three categories: Individual loan components, portfolio components, and additional ABS features. Individual loan components comprise maturity, credit quality, and credit migration probability, and expected recovery rate at default. Portfolio components comprise the sensitivities of the individual loans to the common factor, portfolio diversification, and individual obligor concentration. Furthermore, in practice, ABS portfolios present additional complications as they are dynamic portfolios with various restrictions concerning asset replenishment over the lifetime of the issue. The implementation applied in this paper accounts for single issuer default as well as portfolio characteristics, which are the focus of the investigation.

\subsection{Base Case}

We now investigate the nature of risk transfer from the underlying portfolio to tranches. This is at the heart of structured finance transactions, i.e. the pooling and reallocation of individual risks to investors. The transfer of risks is non-proportional, due to the principle of subordination of tranches. The resulting risk allocation is estimated by Monte Carlo simulation.

Let us consider as base case a reference portfolio with 10,000 loans. All securities have the same characteristics: They are zero bonds with identical nominal value, 10 years to maturity, $7.63 \%$ default probability, $24.15 \%$ recovery rate, and identical exposure to the macro factor, corresponding to a correlation of $\rho_{n}^{M}=0.15$ between all securities. The applied default probability corresponds to a Baa-rating for the bonds, according to Moody's (2005), Exhibit 17. Overall, the base case represents a realistic setting for a typical ABS transaction. The high number of loans is chosen intentionally to eliminate diversifiable risk to a large extent. The evolution of individual-loan credit quality over time is simulated with 500,000 simulation runs. 
Subsequently, following industry practice in the securitization market, the portfolio is split into several tranches of strict subordination. In the subsequent analysis, the number of tranches is assumed to be seven. Note that all results reported below remain essentially unchanged if the number of tranches is smaller or larger, say 5 or 9 . In practice, the tranches are associated with different ratings by rating agencies. For given maturities of the tranches, the ratings in turn correspond to specific default probabilities. We define the tranches by a maximum default probability, which is fixed at the $1.01 \%, 2.57 \%, 3.22 \%, 7.63 \%, 19 \%$, and $36.51 \%$ quantile of the loss rate distribution. These numbers correspond to the average issuer-weighted cumulative default rates by whole letter rating for the period from 1920 to 2004 as reported by Moody's (2005). Thus, the six most senior tranches are rated Aaa, Aa, A, Baa, Ba, and B according to Moody's rating scheme, while the remaining first loss piece is not rated. We number the tranches from 1 to 7 , with the seventh tranche being the first loss piece, or equity piece, which covers the residual loss. Tranche no.1, at the other end of the spectrum, refers to the most senior tranche. All remaining tranches, nos. 2-6, are mezzanine tranches.

Tranching is done with the intention of maximizing the size of each tranche except the first loss piece, subject to the restrictions that the sizes of all more senior tranches are maximized and the default probability of that tranche is not greater than that required to obtain a particular credit rating. Thus, a portfolio is tranched by first determining the lower attachment points of all tranches. The lower attachment point of each tranche is given as the portfolio loss rate that is exceeded only with the default probability allowed for that tranche. Since the upper attachment point of a tranche is identical to the lower attachment point of the next senior tranche, the size of each tranche is given as the difference between the two attachment points of that tranche. Thus, the number of different layers (tranches) and their required maximum default probabilities, determined by the rating a tranche is supposed to have, determine the attachment points and, correspondingly, the sizes of the tranches.

Applying the presented loss distribution of the total portfolio leads to the following tranche sizes, represented as fraction of the total portfolio, starting from the most senior tranche: 0.7853 , $0.0385,0.0092,0.0371,0.0397,0.0295$, and 0.0607 for the equity piece. The detailed summary statistics for the tranches are provided in Panel A of Table 1.

As can be seen in Panel A of Table 1, the senior tranche is by far the largest part of the entire transaction, making up $78.53 \%$ of the transaction. The expected loss rate is only 5 basis points, while expected loss given a default event is 495 basis points. The mean loss rate is monotonic increasing in the degree of subordination. Its maximum value is $69.01 \%$ for the 
equity piece. The default probability of the equity piece is $100 \%$, as none out of 500,000 runs in the simulation came out with a zero loss rate for the entire portfolio.

The senior tranche has the highest quality in all categories. The probability of default is lowest, with no loss in $98.99 \%$ of all cases in this example. In addition, mean loss, loss standard deviation, and loss given default are lowest among all tranches. Furthermore, the senior tranche is by far the largest of all tranches, with a claim on $78.53 \%$ of the volume of the underlying portfolio in the base case. In contrast to the senior tranche, the first loss piece suffers a loss rate of $100 \%$ with a large probability of $36.51 \%$. Furthermore, while low losses occur at low frequency, higher losses occur with an increasing likelihood, peaking at a loss of $36 \%$ in the base case. Overall, the first loss piece (FLP) has the highest expected loss of all tranches.

The numbers for the senior tranche are particularly striking, as they show a very low mean loss given default, despite its large size. Realized portfolio losses that surpass the capacities of the more subordinate tranches cluster at the low end of possible loss rates, without any observation exceeding a $40 \%$ loss rate in the simulation runs. Clearly, the shape of the loss distribution for this tranche (as for the other tranches as well) depends on the shape of the total portfolio loss distribution and the applied tranching scheme. However, the differences are typically not very pronounced and affect characteristics such as the steepness of the distribution.

Overall, the obtained results for the base case are typical for real-world securitization transactions. To check the stability of the results, the base case is altered with respect to three selected key characteristics of the reference portfolio. In particular, the correlation coefficient is increased to 0.3 , the default probability is increased to 0.19 , and the number of loans in the portfolios is reduced to 100 . The resulting tranche statistics obtained when tranching these portfolios with the same tranching scheme as applied for the base case are given in Panels B, C, and D of Table 1.

Higher correlation (Panel B) than in the base case leads to a more fat-tailed portfolio loss distribution while mean loss is not affected. More extreme loss realizations lead to smaller sizes of extreme tranches (tranche no.1 and tranche no.7) and larger sizes of mezzanine tranches. This can be seen in Panel B. In Panel C, the default probability is increased from 0.0763 to 0.19, corresponding to a one notch downgrade, from Baa to Ba, according to Moody's tables. Increased default probability directly affects the mean loss of the reference portfolio and it also leads to increased mean loss of all the tranches compared to the base case. Decreasing the number of loans in the reference portfolio, as shown in Panel D, does not systematically change 
the results compared to the base case.

Overall, we find the results in the base case to be robust with respect to changes of the portfolio characteristics. While, of course, the numbers do change, the qualitative findings are unchanged.

From the simulation exercise, we obtain a couple of insights. By tranching, the risks of the underlying portfolio are allocated in a non-proportional way to the tranches. The loan portfolio is transformed into several securities with entirely different risk characteristics. The presented statistics illustrate that reference portfolios of average quality (a $7.63 \%$ default probability over 10 years for all loans, conforming to a Baa rating, according to Moody's) can be divided into one large tranche of the highest quality, a couple of mezzanine tranches, and a relatively small first loss piece in which the major proportion of credit risk is concentrated. The tranches or only a selection of them, as is often intended, can subsequently be sold to investors.

\subsection{A real-world example: The London Wall transaction}

Naturally, the presented modeling techniques can be applied not only to well-defined model cases, but also to real-world transactions. As an example, we perform all calculations for Deutsche Bank's London Wall 2002-2 transaction.

Figure 1 shows the structure of the London Wall 2002-2 transaction. The securitized reference portfolio has a value of 1.8 billion Euro. It is split into twelve tranches of different seniority (as an exception, the tranches A1 and A2 as well as B1 and B2 do have the same seniority - they are just issued in different currencies). Of these twelve tranches, eleven tranches are rated, corresponding to $97.39 \%$ of the nominal value of the transaction. The biggest part of the nominal value $(84.49 \%)$ is covered by the most senior tranche (in the London Wall case the Senior Credit Default Swap). The most junior tranche, i.e. the first loss piece, is not rated. It amounts to a comparably tiny $2.61 \%$ of the nominal value.

Figure 2 shows the loss distribution of the reference portfolio and depicts, how the reference portfolio is split into tranches. Note that the horizontal axis is truncated at $10 \%$, implying that the loss distribution is concentrated at the very left end of the entire range. This means that small losses do occur and are quite likely, while large losses essentially do not occur. This structure leads to a rather small first loss piece where most the probability mass in concentrated, and a huge, safe senior tranche. 
Overall, the numbers show that the obtained results also apply for real-world transactions.

\section{Deriving a standardized skin-in-the-game metric for the use of regulators and rating agencies}

\subsection{The Retention Metric}

We will now develop a simple metric capturing the extent to which the issuer has skin-in-thegame by retaining a certain portion of the securitization transaction. The basic idea is to measure the magnitude of potential default losses that is included in the retained $5 \%$, according to the retention option chosen by the issuer.

The goal is to achieve a suitable, incentive-conscious retention metric. This metric should be based on retained (expected) default losses as a reflection of the skin-in-the-game (rather than the nominal value of the retained portion). Thus, we propose the retention metric $R M$, capturing the portion of overall portfolio losses that is retained by the originator. Formally, it can be defined as follows:

$$
R M=\frac{s_{r} \cdot \int_{P} L R R \mathrm{~d} p}{s_{P F} \cdot \int_{P} P L R \mathrm{~d} p},
$$

where LRR is the loss rate of the retained portion, PLR is the portfolio loss rate, $s_{r}$ is the nominal size of the retained portion, and $s_{P F}$ is the nominal size of the securitized portfolio.

Note that $R M$ is bound by zero and one. $R M$ equals one if all possible losses are borne by the originator. Similarly, $R M$ equals zero if no losses are retained. For partial retention, $R M$ takes values between zero and one. By construction, retaining more junior tranches automatically leads to a higher value of $R M$ as compared to retaining more senior tranches of equal size.

The $R M$ metric has several useful properties. It is easy to understand and it is normalized to the interval between zero (for no retention at all) and one (for full retention), i.e. the metric rises with the extent to which default losses are retained.

Another property of the metric is that it naturally gives first losses higher weight than second and higher losses - reflecting the fact that first (or junior) losses have a stronger effect on 
effort choice by the issuer/originator than subsequent (or more senior) loss events. Retaining a fraction of a senior tranche entails very little default risk, since the default probability of a AAA tranche, and equally its loss given default, tend to be very small. Moreover, the default event that triggers losses at an AAA tranche will, in all likelihood, be driven by economy-wide shocks rather than by individual, firm-specific decisions under the control of firm management. Hence, the retention of a senior tranche, or parts thereof, will have very limited, if not zero positive incentive effects.

\subsection{Applying the retention metric to the proposed retention options}

Next, we apply the new retention metric $R M$ to major admissible options under the existing regulatory regimes in the EU and the US. Note that the menu of options is similar in the EU and the US, both focusing on horizontal and vertical rules, and combinations of those. While the EU bases its rules on nominal (face) values of exposures, the US rules refer to fair (market) values. Both procedures lead to similar results.

Table 2 presents comparative results of the retention metric for four retention options (a)-(d) listed in CRD IV, Article 405, including the two best-known retention models, namely the vertical and the horizontal retention rule, options (a) and (d) in Art. 405. Whereas options (a) and (d) reference securitization tranches, retention options (b) and (c) reference individual securitization exposures (e.g. loans).

The estimation in Panel A is done on the basis of the numerical example used in the previous section, i.e. a large number of independently distributed assets, with default rate $7.63 \%$ combined with a positive pairwise correlation coefficient of 0.15 and a given LGD of 0.76 . The entries in the last column contain the results for the retention metric $R M$, the percentage of expected loss due to asset default that is kept in the books of the issuer, and thus qualifies as default risk retention. The retention statistic is defined in the range zero (for no retention) to one (for full retention).

Panels B, C and D report the results for the same retention statistic, using different assumptions for the underlying simulation exercise. In Panel B, the correlation between any two assets is increased from the low level of $\rho=0.15$ in the base case, to a higher value of $\rho=0.3$. In Panel $\mathrm{C}$, the default probability of the individual assets is increased from $\mathrm{p}=7.63 \%$ (in the base case) to $\mathrm{p}=19 \%$ and in Panel $\mathrm{D}$, the number of loans is decreased from $\mathrm{n}=10,000$ (in the base

case) to $\mathrm{n}=100$. Finally, Panel $\mathrm{E}$ reports the corresponding numbers for a real-world example, 
the London Wall 2002-2 transaction.

As is evident from comparison among the last column of the Panels in Table 2, for the retention options (a), (b), and (c), the metric $R M$ turns out to be a constant, and invariant against a change of the modeling assumptions. This means that the three retention options (a), (b), and (c) are equivalent - they all imply the same degree of skin-in-the-game. Moreover, that level is already determined by the retention volumne (i.e. 5\%), and it is the same irrespective of the composition of the portfolio and portfolio quality.

In contrast, option (d) implies a completely different level of skin-in-the-game. The retention metric $R M$ takes values much larger than $5 \%$. In the base case, $R M$ is equal to $59.55 \%$ more than ten times as much as in options (a) to (c). A comparison of Panels A, B, C, and D shows that only for option (d), the $R M$-statistic is sensitive to the properties of the underlying asset portfolio. In the model case of Table 2, holding constant the retained horizontal retention piece (option (d)), higher underlying asset default risk, higher correlation among assets, and smaller number of assets in the securitized portfolio lead to a smaller proportion of expected default loss that is actually retained by the issuer.

Panel E in Table 2 presents the same statistic for the real-world case London Wall, a synthetic securitization issued in 2002, which has also been introduced in Section 3.4 of the paper. As is evident from looking at Table 2, the attained level of retention varies greatly across the retention options. We find the highest $R M$ statistic by far for option (d) under all variations of model assumptions. Expected loss withholding amounts to as much as $99.9 \%$ for the London Wall 2002 case. In this transaction, a first loss piece of $5 \%$ would absorb almost all losses, making the more senior tranches almost completely safe. Again, all other retention options produce an expected loss retention of $5 \%$, that is smaller by an order of magnitude. These numbers illustrate the dramatical difference of the retention options. In all conceivable securitization cases, the (d)-option yields a much stronger incentive alignment between management and investors than any of the other options.

In the case of option (c), an additional consideration may be done. Given the random selection of withheld assets in this option, it may even be argued that actual retention is zero, as there is no skin in the game remaining for the securitized assets. Option (c) only requires the issuer to keep an ongoing and qualitatively similar asset pool on its books. It is debatable whether such a withholding construction actually induces ongoing monitoring incentives for those assets that have been securitized. 


\section{Implications for policy makers, regulators, and rating agencies}

In this paper we have developed a new measure of risk retention in ABS transactions. The retention metric $R M$ expresses the share of expected losses retained by the originator in a single number, ranging from zero to one, i.e. from no expected losses retention to full retention. In the previous section we have shown that existing retention rules under Europe's CRR, and similarly for the US' Dodd-Frank Act, emphasize the importance of retention for better securitizations. Both legislations offer a menu of retention options that differ significantly as to the actual level of retained default risk. When applying our retention metric to major admissible options under the existing regulatory regimes in the EU and the US, we find that, for the same securitization transaction, retention can be very small (close to zero) under one option and very large (close to $100 \%$ ) under another option. This in itself is a troubling finding, given that risk retention is the explicit objective of the regulation in the EU and the US. If the options imply very different retention levels, and if issuers can self-select, then what has the regulation actually achieved in terms of originator/issuer deductible?

The answer to this question is disappointing: not much at all. It seems that issuers can easily avoid having substantial skin in the game, simply by selecting an option that does not tie retention to the first loss piece, like options (a), (b), and (c) of CRR, Article 405, or the vertical option under under the Dodd-Frank Act, SEC (2014)). Under these retention rules, the effective retention is merely $5 \%$ of the expected loss of the issue - which is arguably a small number. Under the current regulation, only horizontal retention -option (d)- fulfills the expectation of a significant deductible for the issuer. Thus, if the objective of the ABS retention rules is to tie risk incentives to the originator, by giving him/her a significant ex-ante stake in ex-post risk realizations, then option (d) is a much more convincing stipulation than any of the other existing alternative rules. Particularly CRR's option (c) may effectively be empty, since there is no skin in the game remaining for securitized assets.

Not only does the true retention level vary widely across available options, also the market remains uninformed about the retention option chosen and the implied level of skin in the game. On a deeper level, the true problem with the current state of retention regulation is the lack of disclosure and transparency. Investors simply do not know the actual retention level of a given transaction and the implications for the originators behavior. As a negative consequence, the lack of retention transparency will affect the functioning of the market for ABS securities, possibly leading to higher funding costs, lower liquidity, and smaller issue volumes, decreasing 
the attractiveness of this class of instruments. Thus, the legal requirement of $5 \%$ minimum retention is void as long the effective level of default risk retention is undisclosed.

What are the options for policy makers in their attempt to develop a better regulation for simple and transparent securitizations? The first option is to require horizontal retention as the only way to fulfill the $5 \%$ minimum retention requirement. This always implies more retention than in any other option. However, generally requiring 5\% retention might not be optimal. Moreover, the actual level of retention depends on portfolio characteristics and may vary from transaction to transaction. Thus, a second option is to require a given value of retention as defined by our retention metric $R M$, irrespective of how that critical value is reached, through vertical or horizontal retention. This approach is suitable if there exists an optimal level of retention and it is known. As third option, the regulator could just impose ongoing transparency about retention by making $R M$-disclosure compulsory for all ABS issues. This option combines transparency about risk retention with complete freedom about securitization design. The preferences of investors and issuers will decide - and the market can differentiate between retention levels, and will set prices accordingly. This will help to improve market quality, and may eventually increase the attractiveness of ABS as a funding instrument.

Whatever option is chosen, a market standard for retention reporting is needed. If the effective retention level of each transaction would be disclosed publicly, using the retention metric $R M$ proposed in this paper, the complexity of ABS products would be greatly reduced. Moreover, a comparison between different ABS products would be much easier with an explicit, public retention measure; a major determinant of quality differences among different issues is now visible after all. Both aspects, reduced complexity and improved comparability among products, are likely to enhance the development of a transparent and liquid secondary market for ABS tranches.

As far as implementation of a mandatory retention metric is concerned, market institutions and regulatory institutions both could play a role. On the market side, rating agencies can calculate $R M$. This is a model-based exercise, and agencies are well prepared to carry out such a task during the issue process. Note, the numerical securitization model presented in section 3 of this paper, which is the workhorse for calculating $R M$, builds on the valuation models developed and applied by major rating agencies since the 1990s, like Moody's and Standard \& Poors, see Cantor et al. (2002). $R M$-values could be published by the agencies prior to the initial public offering, along with further rating information. The market regulator ESMA could oversee the agencies with respect to the quality of their $R M$ assessment. 
Table 1: Summary statistics for tranches

This table presents summary statistics for the seven tranches, representing claims of strict subordination on the underlying portfolio. The statistics indicate the allocation of losses of the underlying portfolio to the individual tranches. The cut-off values for a particular tranche is determined by the default probability allowed for that tranche as indicated in the fifth column and the default probability allowed for the next senior tranche. The most junior tranche (tranche number 7) corresponds to the first loss piece. It bears the first losses occurring in the portfolio, and only when its capacity is exhausted does the next senior tranche take on losses. The columns present, from left to right, tranche number, tranche size, mean loss, loss standard deviation, default probability, and mean loss given default (LGD). The last row of each panel displays the statistics for the underlying portfolio. In Panel A (base case), the reference portfolio consists of 10,000 zero bonds, and all of them are assumed to have a default probability of $7.63 \%, 10$ years maturity, $24.15 \%$ recovery rate, and a default correlation of 0.15 . The loss distribution is calculated with 500,000 simulations. In Panel B, the base case is altered and the default correlation is increased to 0.3. Panel $\mathrm{C}$ applies the portfolio characteristics of the base case, except the default probability, which is increased to $19 \%$. In Panel D, the settings of the base case are applied, with the exception that the number of loans in the reference portfolio is 100 .

\begin{tabular}{|c|c|c|c|c|c|}
\hline \multicolumn{6}{|c|}{ Panel A: Base case } \\
\hline Tranche & size & mean loss & loss std & default prob & mean LGD \\
\hline (Aaa) 1 & $78.53 \%$ & $0.05 \%$ & $0.69 \%$ & $1.01 \%$ & $4.95 \%$ \\
\hline 2 & $3.85 \%$ & $1.68 \%$ & $11.82 \%$ & $2.57 \%$ & $65.47 \%$ \\
\hline 3 & $0.92 \%$ & $2.88 \%$ & $16.41 \%$ & $3.22 \%$ & $89.54 \%$ \\
\hline 4 & $3.71 \%$ & $5.12 \%$ & $20.32 \%$ & $7.63 \%$ & $67.04 \%$ \\
\hline 5 & $3.97 \%$ & $12.47 \%$ & $30.07 \%$ & $19.00 \%$ & $65.61 \%$ \\
\hline 6 & $2.95 \%$ & $26.79 \%$ & $40.89 \%$ & $36.51 \%$ & $73.37 \%$ \\
\hline$(\mathrm{FLP}) 7$ & $6.07 \%$ & $69.01 \%$ & $31.01 \%$ & $100.00 \%$ & $69.01 \%$ \\
\hline Total PF & $100.00 \%$ & $5.79 \%$ & $4.55 \%$ & $100.00 \%$ & $5.79 \%$ \\
\hline \multicolumn{6}{|c|}{ Panel B: Different correlation $(\rho=0.3)$} \\
\hline Tranche & size & mean loss & loss std & default prob & mean LGD \\
\hline (Aaa) 1 & $67.72 \%$ & $0.10 \%$ & $1.31 \%$ & $1.01 \%$ & $9.80 \%$ \\
\hline 2 & $7.02 \%$ & $1.69 \%$ & $11.84 \%$ & $2.57 \%$ & $65.66 \%$ \\
\hline 3 & $1.71 \%$ & $2.88 \%$ & $16.40 \%$ & $3.22 \%$ & $89.45 \%$ \\
\hline 4 & $6.85 \%$ & $5.11 \%$ & $20.30 \%$ & $7.63 \%$ & $66.93 \%$ \\
\hline 5 & $6.93 \%$ & $12.39 \%$ & $29.99 \%$ & $19.00 \%$ & $65.19 \%$ \\
\hline 6 & $4.52 \%$ & $26.57 \%$ & $40.79 \%$ & $36.51 \%$ & $72.76 \%$ \\
\hline$(\mathrm{FLP}) 7$ & $5.25 \%$ & $60.11 \%$ & $37.51 \%$ & $99.87 \%$ & $60.19 \%$ \\
\hline Total PF & $100.00 \%$ & $5.80 \%$ & $6.89 \%$ & $99.87 \%$ & $5.81 \%$ \\
\hline \multicolumn{6}{|c|}{ Panel C: Different default probability $(p=0.19)$} \\
\hline Tranche & size & mean loss & loss std & default prob & mean LGD \\
\hline (Aaa) 1 & $61.32 \%$ & $0.07 \%$ & $0.93 \%$ & $1.01 \%$ & $6.93 \%$ \\
\hline 2 & $4.72 \%$ & $1.69 \%$ & $11.86 \%$ & $2.57 \%$ & $65.86 \%$ \\
\hline 3 & $1.23 \%$ & $2.88 \%$ & $16.40 \%$ & $3.22 \%$ & $89.48 \%$ \\
\hline 4 & $5.18 \%$ & $5.15 \%$ & $20.39 \%$ & $7.63 \%$ & $67.53 \%$ \\
\hline 5 & $6.28 \%$ & $12.60 \%$ & $30.22 \%$ & $19.00 \%$ & $66.33 \%$ \\
\hline 6 & $5.34 \%$ & $27.02 \%$ & $41.00 \%$ & $36.51 \%$ & $74.01 \%$ \\
\hline$(\mathrm{FLP}) 7$ & $15.93 \%$ & $73.83 \%$ & $27.27 \%$ & $100.00 \%$ & $73.83 \%$ \\
\hline Total PF & $100.00 \%$ & $14.42 \%$ & $8.22 \%$ & $100.00 \%$ & $14.42 \%$ \\
\hline \multicolumn{6}{|c|}{ Panel D: Different number of loans (100 loans) } \\
\hline Tranche & size & mean loss & loss std & default prob & mean LGD \\
\hline (Aaa) 1 & $77.24 \%$ & $0.05 \%$ & $0.72 \%$ & $1.01 \%$ & $5.12 \%$ \\
\hline 2 & $4.55 \%$ & $1.73 \%$ & $11.88 \%$ & $2.57 \%$ & $67.22 \%$ \\
\hline 3 & $0.76 \%$ & $3.02 \%$ & $17.12 \%$ & $3.22 \%$ & $93.92 \%$ \\
\hline 4 & $3.79 \%$ & $5.16 \%$ & $20.54 \%$ & $7.63 \%$ & $67.60 \%$ \\
\hline 5 & $4.55 \%$ & $12.77 \%$ & $30.28 \%$ & $19.00 \%$ & $67.22 \%$ \\
\hline 6 & $3.04 \%$ & $27.66 \%$ & $41.64 \%$ & $36.51 \%$ & $75.75 \%$ \\
\hline (FLP) 7 & $6.07 \%$ & $66.45 \%$ & $34.21 \%$ & $95.18 \%$ & $69.81 \%$ \\
\hline Total PF & $100.00 \%$ & $5.79 \%$ & $4.95 \%$ & $95.18 \%$ & $6.09 \%$ \\
\hline
\end{tabular}


Table 2: Retention metric

This table presents, for the base case example, the retention metric as applied to the different retention options according to CRD IV and DFA. The columns present, from left to right, name of regulation, description of regulation, size of retention, mean loss of retained portion, and retention metric. In Panel A (base case), the reference portfolio consists of 10'000 zero bonds, and all of them are assumed to have a default probability of $7.63 \%, 10$ years maturity, $24.15 \%$ recovery rate, and a default correlation of 0.15 . The loss distribution is calculated with 500'000 simulations. In Panel B, the base case is altered and the default correlation is increased to 0.3. Panel $\mathrm{C}$ applies the portfolio characteristics of the base case, except the default probability, which is increased to $19 \%$. In Panel D, the settings of the base case are applied, with the exception that the number of loans in the reference portfolio is 100. In Panel E, the numbers are shown for a real-world transaction (London Wall 2002-2).

\begin{tabular}{|c|c|c|c|c|}
\hline \multicolumn{5}{|c|}{ Panel A: Base case } \\
\hline Regulation & Description & size of retention & mean loss & Retention metric \\
\hline$\overline{\mathrm{EU}}$ a) & $5 \%$ of each tranche & $5 \%$ & $5.79 \%$ & $5.00 \%$ \\
\hline EU b) & $5 \%$ of each individual exposure & $5 \%$ & $5.79 \%$ & $5.00 \%$ \\
\hline $\mathrm{EU}$ c) & $5 \%$ of randomly selected exposures & $5 \%$ & $5.79 \%$ & $5.00 \% / 0 \%$ \\
\hline EU d) & $5 \%$ horizontal slice (first loss) & $5 \%$ & $69.01 \%$ & $59.55 \%$ \\
\hline \multicolumn{5}{|c|}{ Panel B: Different correlation $(\rho=0.3)$} \\
\hline Regulation & Description & size of retention & mean loss & Retention metric \\
\hline$\overline{\mathrm{EU}}$ a) & $5 \%$ of each tranche & $5 \%$ & $5.80 \%$ & $5.00 \%$ \\
\hline EU b) & $5 \%$ of each individual exposure & $5 \%$ & $5.80 \%$ & $5.00 \%$ \\
\hline $\mathrm{EU}$ c) & $5 \%$ of randomly selected exposures & $5 \%$ & $5.80 \%$ & $5.00 \% / 0 \%$ \\
\hline EU d) & $5 \%$ horizontal slice (first loss) & $5 \%$ & $60.11 \%$ & $51.82 \%$ \\
\hline \multicolumn{5}{|c|}{ Panel C: Different default probability $(p=0.19)$} \\
\hline Regulation & Description & size of retention & mean loss & Retention metric \\
\hline EU a) & $5 \%$ of each tranche & $5 \%$ & $14.42 \%$ & $5.00 \%$ \\
\hline $\mathrm{EU} b)$ & $5 \%$ of each individual exposure & $5 \%$ & $14.42 \%$ & $5.00 \%$ \\
\hline $\mathrm{EU}$ c) & $5 \%$ of randomly selected exposures & $5 \%$ & $14.42 \%$ & $5.00 \% / 0 \%$ \\
\hline EU d) & $5 \%$ horizontal slice (first loss) & $5 \%$ & $73.83 \%$ & $25.60 \%$ \\
\hline \multicolumn{5}{|c|}{ Panel D: Different number of loans (100 loans) } \\
\hline Regulation & Description & size of retention & mean loss & Retention metric \\
\hline$\overline{\mathrm{EU}}$ a) & $5 \%$ of each tranche & $5 \%$ & $5.79 \%$ & $5.00 \%$ \\
\hline EU b) & $5 \%$ of each individual exposure & $5 \%$ & $5.79 \%$ & $5.00 \%$ \\
\hline EU c) & $5 \%$ of randomly selected exposures & $5 \%$ & $5.79 \%$ & $5.00 \% / 0 \%$ \\
\hline EU d) & $5 \%$ horizontal slice (first loss) & $5 \%$ & $66.45 \%$ & $57.36 \%$ \\
\hline \multicolumn{5}{|c|}{ Panel E: Real-world example (London Wall transaction) } \\
\hline Regulation & Description & size of retention & mean loss & Retention metric \\
\hline$\overline{\mathrm{EU}}$ a) & $5 \%$ of each tranche & $5 \%$ & $1.50 \%$ & $5.00 \%$ \\
\hline $\mathrm{EU} b)$ & $5 \%$ of each individual exposure & $5 \%$ & $1.50 \%$ & $5.00 \%$ \\
\hline $\mathrm{EU}$ c) & $5 \%$ of randomly selected exposures & $5 \%$ & $1.50 \%$ & $5.00 \% / 0 \%$ \\
\hline $\mathrm{EU}$ d) & $5 \%$ horizontal slice (first loss) & $5 \%$ & $29.94 \%$ & $99.90 \%$ \\
\hline
\end{tabular}


Figure 1: Overview of the London Wall 2002-2 transaction

This diagram presents the structure of Deutsche Bank's London Wall 2002-2 transaction, based on Moody's New Issue Report.
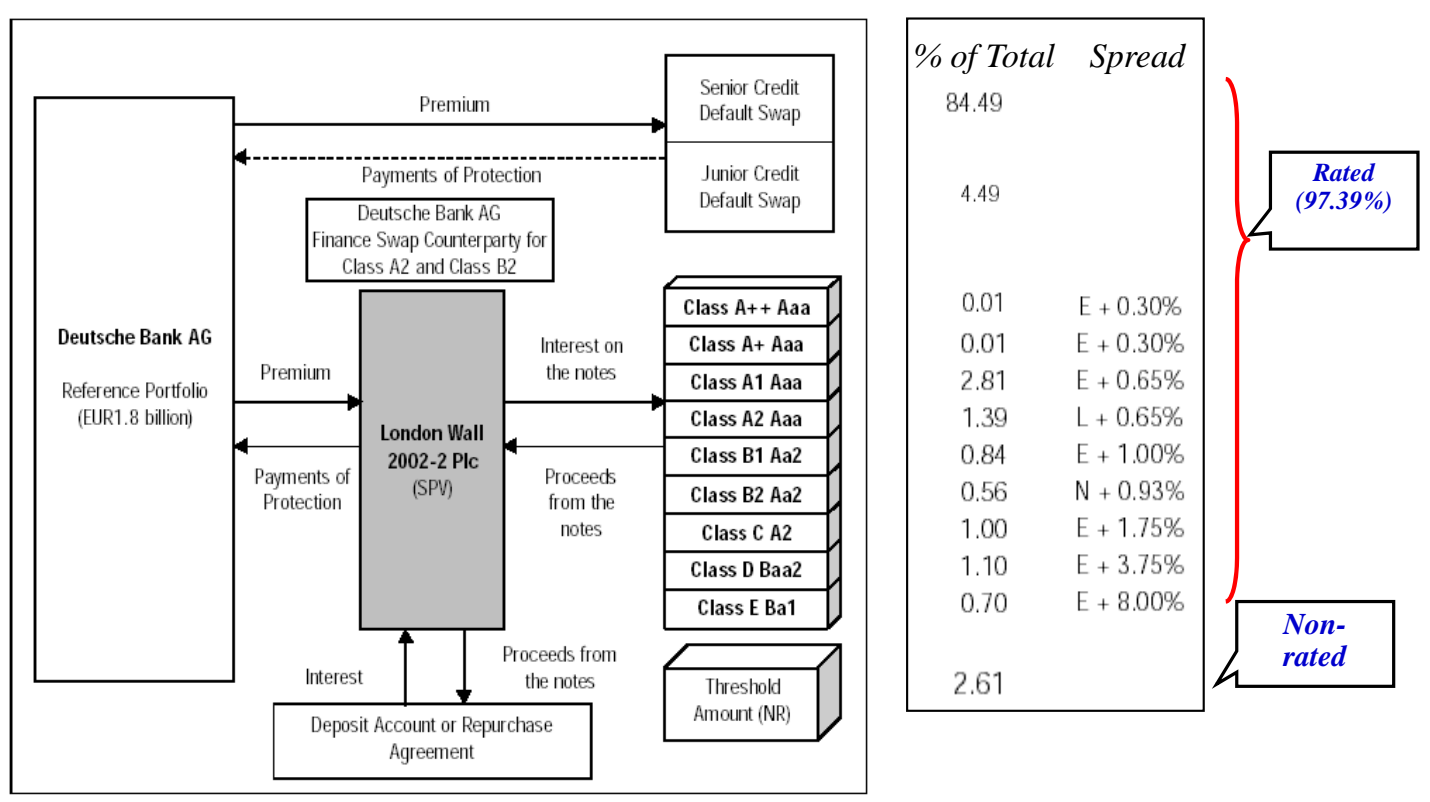
Figure 2: Real-world tranching example: The London Wall 2002-2 transaction

This diagram presents the simulated loss distribution of Deutsche Bank's London Wall 2002-2 transaction and the corresponding tranches. Relevant information on the reference portfolio as provided in the offering circular is used as basis for the simulations. The assumed correlation structure is 0.3 within industries, and 0 between industries. Credit migration risk is modeled according to Standard and Poor's rating migration table. The horizontal axis denotes the portfolio loss rate (PLR), and the vertical axis denotes the associated probabilities based on 50'000 simulation runs.

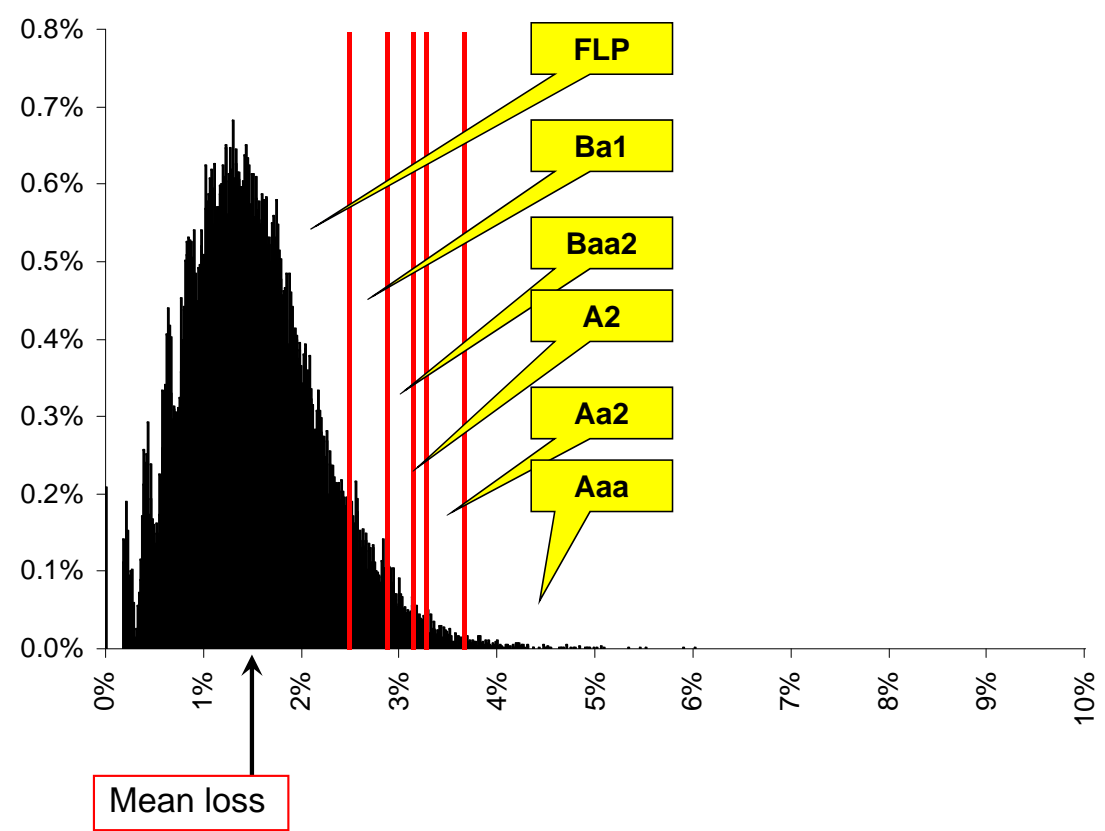




\section{References}

Ashcraft, A., Gooriah, K., Kermani, A., 2014. Does skin-in-the-game affect security performance? evidence from the conduit cmbs market. Working paper, Federal Reserve Bank of New York and University of California, Berkeley.

Ashcraft, A., Schuermann, T., 2007. Understanding the securitization of subprime mortgage credit. Working paper Federal Reserve Bank of New York.

Begley, T., Purnanandam, A., 2013. Design of financial securities: Empirical evidence from private-label rmbs deals. Working paper, Ross School of Business, University of Michigan.

Cantor, R., Fons, J., Mann, C., 2002. Understanding Moody's corporate bond rating and rating process. Special comment. Technical Report. Moody's Investor Service, Report 74982.

Chemla, G., Henessy, C., 2014. Skin in the game and moral hazard. Journal of Finance 69, $1597-1641$.

Coval, J., Jurek, J., Stafford, E., 2009. Economic catastrophe bonds. American Economic Review 99, 628-666.

DeMarzo, P., 2005. The pooling and tranching of securities: a model of informed intermediation. Review of Financial Studies 18, 1- 35.

DFA, 2010. Dodd Frank Wall Street Reform and Consumer Protection Act. Technical Report. US Congress, Document H.R. 4173.

EC, 2013. Regulation on prudential requirements for credit institutions and investment firms and amending Regulation (CRR) (EU) No 648/2012, Document (EU) No 575/2013. Technical Report.

Fons, J., 2008. Credit rating agencies and the financial crisis - Written testimony before the U.S. House Committee of Oversight and Government Reform. Technical Report. Moody's.

Franke, G., Herrmann, M., Weber, T., 2012. Loss allocation in securitization transactions. Journal of Financial and Quantitative Analysis 47, 1125-1153.

Franke, G., Krahnen, J.P., a. Default risk sharing between banks and markets: the contribution of collateralized debt obligations, in: Carey, M., Stulz, R. (Eds.), The Risks of Financial Institutions, 2006. 
Franke, G., Krahnen, J.P., b. The future of securitization, in: Fuchita, Y., Herring, R., Litan, R. (Eds.), Prudent Lending Restored - Securitization After the Mortgage Meltdown, 2009.

Gorton, G., Metrick, A., 2012. Securitized banking and the run on repo. Journal of Financial Economics 104, 425-451.

Gorton, G., Pennacchi, G., 1995. Banking and loan sales: Marketing non-marketable assets. Journal of Monetary Economics 35, 389-411.

Hartman-Glaser, B., Piskorski, T., Tchistyi, A., 2012. Optimal securitization with moral hazard. Journal of Financial Economics 104, 186-202.

Hellwig, M., 2009. Systemic risk in the financial sector: An analysis of the subprime mortgage financial crisis. De Economist 157, 129-207.

Hänsel, D., Krahnen, J.P., 2008. Does credit securitization reduce bank risk? evidence from the european cdo market. Working paper, Finance Department, Goethe University Frankfurt.

Hébert, B., 2015. Moral hazard and the optimality of debt. Working paper, Stanford University. Innes, R.D., 1990. Limited liability and incentive contracting with ex-ante choices. Journal of Economic Theory 52, 45-67.

Jensen, M., Meckling, W., 1976. Theory of the firm: Managerial behavior, agency costs and the ownership of the firm. Journal of Financial Economics 3, 305-360.

Kara, A.; Marquez-Ibanez, D.O.S., 2015. Securitization and credit quality. International Finance Discussion Paper, Board of Governors of the Federal Reserve System.

Keys, B., Mukherjee, T., Seru, A., Vig, V., 2010. Did securitization lead to lax screening? evidence from subprime loans. Quarterly Journal of Economics 125, 307-362.

Krahnen, J.P., Wilde, C., 2014. Cdos and systematic risk: Why bond ratings are inadequate. Working paper, Goethe University Frankfurt.

Moody's, 2005. Default and recovery rates of corporate bond issuers, 1920-2004. Technical Report. Global Credit Research, Moody's Investors Service, January 2005.

Scholz, M., 2014. Securitization and credit risk: Evidence from retained interest in securitized mortgages. Working paper, Accounting Department, Goethe University Frankfurt.

Schönbucher, P., 2000. Factor models for portfolio credit risk. Working paper, Department of Statistics, Bonn University. 
SEC, 2014. Final rule for implementing credit risk retention. Https://www.sec.gov/rules/final/2014/34-73407.pdf.

Vasicek, O., 1987. Probability of loss on loan portfolio. Working paper, KMV Corporation. 